\title{
Problems and Solutions of the Curriculum Connection from Our Secondary to Higher Vocational School Maohua Xu
}

\author{
Zhejiang Pharmaceutical College, Ningbo, 315100, China
}

Keywords: curriculum connection; secondary and higher vocational school; solution; problem

\begin{abstract}
With the popularization of new curriculum reform, our government increasingly emphasizes on the problems of curriculum connection from secondary to higher vocational schools. However, from the current situation of the curriculum connection from our middle to higher vocational school, it commonly has the following problems such as less modes, small scales of connection, and repeated curriculum content, making our country appears serous wasting phenomenon of teaching resources. In this paper, it analyzes the problems existed in the curriculum connection from our secondary to higher vocational schools, and gives the corresponding solution strategies, so that the curriculum connection from secondary to higher vocational school can be completed smoothly.

In recent years, with the further development of curriculum reform, our country has made great achievements in education. However, in the process of education for students currently, it still faces more important questions, namely are: the small scale and relatively less mode of connection from secondary to higher vocational education, resulting in the serious wasting phenomenon of teaching resources, which brings a lot of thinking to our secondary and higher vocational education. Due to such problems existed in our secondary and higher vocational schools currently, so many students find that the connection between junior high schools and senior high schools is not large, and they think that the high school entrance examination is just a formality. This idea seriously affects the development pace of China's education, so it should be promptly corrected.
\end{abstract}

\section{Analysis on the Current Situation of Curriculum Connection from Secondary to Higher Vocational Schools}

We take Dalian City as an example, to analyze the current situation of curriculum connection from secondary to higher vocational school, and to clear the problems existed in the current curriculum connection from secondary to higher vocational school. Statistics shows that in Dalian city, in terms of connection in the higher vocational school, it has formed four modes through constant practice and development, namely are: counterpart entrance mode, five-year system, " $3+2$ " mode and separated enrollment mode. Although our vocational educational model has made great achievement at this stage, the development in terms of vocational education system is not fully developed, and the vocational education system is not established practically, resulting in that the problems of secondary and higher vocational connection become more and more serious. The problems in the secondary and higher vocational connections are mainly in the following aspects, namely are:

(1) Less connection mode

Less connection mode in our secondary and higher vocational school is a more important issue in terms of the connection problems in the secondary and higher vocational schools. In China, at present, in addition to the four connection modes, there are also some non-academic connection modes in some teaching areas. Through this mode, it allows students who have already reached the level can smoothly receive the higher vocational education, rather than allows the students receive the higher vocational school through the academic ways. For example, currently in Tianjin, it implements the non-academic connection mode, which directly sends the students who win the first and second prize in the competition to the related majors of higher vocational schools for learning and development; while the student won the third prize will formally receive the higher vocational education after meeting all admission standards of the higher vocational schools. In other countries, 
in addition to those connection modes, there are many kinds of connection modes such are vocational qualification and general education, and they also use the applied educational connection mode and integrated curriculum, syllabus connection mode, which also made great achievements in the application; therefore, we should learn from their effective approaches to develop our secondary and higher vocational connection education.

(2) The educational modes in secondary and higher vocational schools are not connected effectively

At present, the educational mode in our secondary and higher vocational schools is not linked effectively. Statistics show that in the end of 2010, it already has 131,000 students under the vocational education, in which there are 103 vocational schools. And in these vocational schools, there are 84,000 students. By 2012, 18 secondary vocational schools and higher vocational schools totally have enrolled 5,557 students, and in the five-year vocational education and those ordinary secondary specialized schools have received 7,885 students. There are also some vocational colleges set up independently, and the students in these colleges have reached 47,000. However, in the future enrollment in Dalian City, it will face a dilemma that the number of student will be less than 1,000. From the survey, we can see that the serious connection problems from secondary to higher vocational schools will be serious, not only in the number of schools, but also in the number of students at school and the enrollment for the secondary and vocational school every year. All of these aspects have serious problems of connection shortage.

(3) There is insufficiency in the curriculum arrangement connection from the secondary to higher vocational schools.

In China, the secondary and higher vocational schools are the teaching with the same type on the different levels. No matter in the depth of theoretical knowledge and the breadth of teaching, or on those practical abilities and personality traits of students, the higher vocational schools are required to take the secondary vocational schools as the basis, and to achieve a higher level and height on this basis. But there are some problems, mostly because we implement the wide enrollment system for those students graduated from the general high schools, so for most of these students, the grasp degree of theoretical and basic knowledge is not very strong, resulting in that in the curriculum setting and some actual operation trainings in our higher vocational schools, they need to grab from the basic knowledge, which leads to the significant repeatability in the curriculum setting in the higher vocational schools. According to the survey, for many schools such as Dalian Vocational Technical College and Dalian Business Schools, their educational means and methods, the degree of difficulty of the curriculum setting and the setting of goals are similar, which give the graduates great competitive risks for their future jobs. From the employment of students in these schools, many graduates are mainly engaged in those business information processing and customer service introductions, which do not meet with the education they actually received. But for the students in Dalian Vocational Technical School majoring in Business Japanese, the number of students who engaged in site translation is less. From these, we can see that in terms of curriculum content setting for the majors in the secondary and higher vocational schools, it is uncontinuous and is serious lack of connection.

\section{Reason Analysis Causing the Problems in the Curriculum Connection from Secondary to Higher Vocational Schools}

There are many reasons causing the problems in the curriculum connection from secondary to higher vocational schools, in which the main reasons are the following two aspects, namely are:

(1) Lacking of governmental management efforts in the aspects of secondary and higher vocational connection

1. The division of market and government in the vocational education is not clear enough, which makes our vocational education does not have effective planned specifications.

Currently, from our secondary and higher vocational education, our government must ensure good management of vocational education. For the market open up and government intervention, it should grasp the relationship between the two, clear the proportion between them, and give 
corresponding encouragement and support in the development. However, our government is lack of management experience in the connection from the secondary to higher vocational schools, and it often appears the inappropriate phenomenon of management efforts. At present, Dalian municipal government is also lack of plans on its specification force in terms of the management in the higher vocational education, so that the vocational education does not have standard and systematic management system, and there is no connection among the elements in the secondary and higher vocational educations, as well as it appears chaotic phenomenon in terms of the setting of majors in the vocational schools.

2. Lack of systematic management

For the management of secondary and higher vocational schools, they belong to different administrative departments. However, in terms of the government management, there is not systematic management. From the management aspect of their subjected department, the secondary vocational schools in Dalian City belong to the management and distribution of Educational Department, while those higher vocational schools belong to the government of Provincial Educational Department, which give the connection from secondary to higher vocational school a certain degree of difficulty. In China, due to the approval and management of running those vocational schools do not have a unified and planned management system, and the majority of private schools are opened for their own development and the creation of more profits, so they do not highly emphasize on the advantages of the schools and the problems of setting up majors for the students, making the connection from secondary to higher vocational education is uncoordinated.

(2) The scope for the higher vocational schools to enroll the graduates from secondary vocational school is too small

Although our higher vocational education is to cultivate more students with high technical level, there are some drawbacks in the enrollment process. In terms of the vocational development of students, its rules are vague and not clear, but it gives a clear emphasis on the vocational aspect of graduates. In addition, many higher vocational schools are established by using the specialized ways, and their ways of enrollment are mainly through the channels of college entrance examination, resulting in the huge insufficiency of enrollment in higher vocational schools, especially in terms of the enrollment of secondary vocational schools, it must be discriminatory.

\section{Optimizing Strategy Analysis on Solving the Curriculum Connection from Secondary to Higher Vocational Schools}

Due to those problems existed in the connection from secondary and higher vocational schools bring a certain negative impact on the development of students, as well as some obstacles on the cultivation of our talents; therefore, the problems in the connection from secondary and higher vocational schools must be solved in a relatively short time to promote the better cultivation of talents.

(1) Formulation of clear training objectives

At present, our understanding of the secondary vocational education is still in the end stage of education, and the positioning direction of higher vocational education is not certain and clear enough, making our connection from secondary to higher vocational education is lack of tightness. For this reason, in order to be able to lay a solid foundation for the connection from secondary to higher vocational schools, it requires to clear the positioning of higher vocational schools. From the employment direction of accounting computerization major in Dalian Business School, there are a lot of recruiting companies for the students; therefore, schools should clear their teaching objectives, formulate the teaching content and setting direction of curriculum according to the employment directions of students, and cultivate students of secondary and higher vocational schools towards this training objective, so that to improve the level and standard of teaching in secondary and higher vocational schools, and to lay a certain foundation of connection from the secondary and higher vocational schools.

(2) Establishment of corresponding organizations to harmoniously conduct the connection from secondary to higher vocational schools 
To ensure the effective connection from secondary to higher vocational schools, the government must firstly establish relevant vocational educational organizations, coordinate various relations in the process of connection from secondary to higher vocational schools, so that to protect the construction work of vocational education system in Dalian City. The specific ways are as follows:

First of all, we should conduct detailed analysis and study on the positions, intelligence, technical essentials of large and medium-sized enterprises with certain representativeness, and use those large and medium-sized enterprises to drive the educational direction of secondary and higher vocational schools, so that to make the industries and enterprises to actively take part in the vocational education, to finally clear that the knowledge needed for the industrial position and the requirements of professional technologies, as well as to ensure the teaching content can be accorded with it.

Secondly, the organizations must take responsibilities for some communication work to make a clear division for the rights and responsibilities of secondary and higher vocational schools, and to have strict requirement on the work and task of secondary and higher vocational schools. Meanwhile, for the educational actions of higher vocational schools, it should give a clear division of labor, form a strong team of teachers, and conduct effective studies on teaching methods, so that to provide a more appropriate teaching method for students to learn

(3) Expand the enrollment proportion of students for the secondary vocational schools

Due to the enrollment proportion of student sources from secondary vocational schools in higher vocational schools is relatively small, so in order to ensure the effectiveness of the connection from secondary to higher vocational schools, we need to expand the enrollment proportion from the secondary vocational schools.

1. The secondary vocational school should effectively reform the entrance examination, detailedly analyze the design and content of curriculum of higher vocational schools, and take the unified standard of enrollment and admission of higher vocational schools as a certain degree of protection. They also can take the examination of each course in the secondary vocational stage as the reference for the future studies in the higher vocational stages; for the higher vocational schools, they should break the enrollment limit, combine with the actual situation, appropriately broaden the condition of examination registration, change the direction of connection from secondary to higher vocational schools, and effectively transfer to focus on teaching content from academic qualifications, to a certain extent, ensuring the expansion of the proportion of counterpart entrance.

2. In addition to the above methods, they also can enroll without requiring entrance examinations. In terms of the secondary vocational schools, they should record the students who are excellent in the moral, intellectual, physical and aesthetic aspects according to the proportion, and send some of those students who are excellent in studying and willing to continue their education after graduation to higher vocational schools without entrance examinations. As a result, we can effectively reduce the expense of labor, money and materials from the counterpart entrance, so that to save the educational resources to some extent and eliminate the wasting phenomenon of teaching resources.

3. Our government should also introduce more policies in this regard, strongly support and encourage the implementation and development of five-year higher vocational education, as well as specifically divide the management and authority for the five-year higher vocational education. Through research and analysis, it should develop reasonable approval criteria of five-year higher vocational education to conduct approval. In addition, it should clear its training objectives, major setting and curriculum design to ensure the effective implementation of five-year higher vocational education.

(4) Effective implementation of the convertible credit

Credit conversion is not unfeasible. Through the conversion of credit, it transfers the final scores of the curriculums learnt in the secondary vocational school into credits, and after entering the higher vocational school, the credits in the secondary vocational school also can be used to ensure that after entering to the higher vocational school, the learning content studied before will not be repeated to avoid the wasting phenomenon of teaching resources. Currently, due to the secondary and higher vocational education belongs to the staged educations, so when the secondary and higher 
vocational education can not be unified immediately, the implementation of credit recognition system will provide a wider space and choice for the students in the secondary vocational schools, and allows students to have a bigger learning independence and selectivity.

\section{Summary}

From the current situation of connection from secondary to higher vocational schools, there are significant problems in curriculum setting, curriculum content and the employment of students in the connection from middle to higher vocational schools. In our country, the connection from secondary to higher vocational schools have the characteristics of less modes, small scales and repeated curriculum content setting, leading to the serious wasting phenomenon of teaching resources in terms of our education, which brings some thoughts to our education circle. There are many reasons causing those problems of our connection from secondary to higher vocational schools, such as the insufficient management of government, uncertainty of position division, etc., which require the education circle combine with the current situation of connection from our secondary to higher vocational schools, to take effective measures to solve the above problems, and to ensure the better development of students.

\section{Acknowledgments}

This paper is the topic of Zhejiang Vocational Education Research in 2011: Study on the professional connection in the higher vocational school - taking the Pharmacy major in Ningbo Economic and Trade School and the Pharmaceutical Formulation Technology major in Zhejiang Pharmaceutical College (ID: YB1166)

\section{References}

[1] Ma Jianfu, How to Connect Secondary Vocational Education with Tertiary Vocational Education [J]. Modern Education Science, 2003 (03).

[2] Zhang Jiahuan, The syncretized design of curriculum structure for the link between secondary VTE and higher VTE [J]. Chinese Vocational and Technical Education, 2006 (31).

[3] Yan Li, Study on the Innovation Ability Training of the Students in the Higher Vocational School [D]. Tianjin University, 2004.

[4] Chen Yuhua, Huang Yuanyuan, Li Xuefeng, An Exploration an d Practice of Personnel Training Mode of Higher Vocational Education During the New Period [J]. Journal of Chengdu Aeronautic Vocational \& Technical College, 2004 (04).

[5] Qin Hong, Problems and Solutions of the connection in the secondary and higher Vocational School [J]. Vocational and Technical Education, 2000 (07). 